\title{
Keep up the pace of drug development evolution and expenditure
}

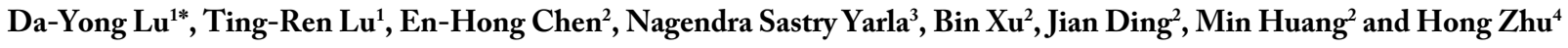 \\ ${ }^{1}$ School of Life Science, Shanghai University, Shanghai, PR China \\ ${ }^{2}$ Shanghai Institute of Materia Medica, Chinese Academy of Sciences, Shanghai201203, PR China \\ ${ }^{3}$ Divisions of Biochemistry and Chemistry, City University of New York School of Medicine, 160 Convent Avenue, New York, NY10031, USA \\ ${ }^{4}$ College of Pharmaceutical Science, Zhejiang University, Hangzhou, PR China
}

\begin{abstract}
Drug development is a pillar industry for many developed countries, yet highly adventurous more recently. Correspondingly, new anticancer drug discovery, development and manufacture norm have been consistently evolving during the past decades. The techniques and tumor models for drug screening create a slow progression of anticancer drug discovery and developments. To promote the efficiency of anticancer drug developments, keeping up the pace of modern anticancer drug development evolution and advances is indispensable. A lot of disciplines need to be noticed and updated. This article addresses important factors affecting the efficiency of anticancer drug developments-including possible innovations of drug screening models, incorporation of latest scientific progresses, cutting-edge technology utility, emerging clinical therapeutic norms (such as personalized medicine and precision medicine) and so on.
\end{abstract}

\section{Background}

\section{Clinical situations of cancer treatment}

Cancer is a malignant disease that is often difficult to be completely cured [1-2]. Despite great advances in recent decades, current cancer therapy still has many limitations, e.g. high costs for conventional therapy, shortage of effective anticancer drugs and high frequency of drug resistance in clinical situations [3-6], especially devoid of effective antimetastatic drugs [7-11]. Lacking reliable therapeutic options targeted for individual cancer patients $[12,13]$ is also an obstacle in clinical cancer treatments. As a result, new actions are needed.

\section{Obstacle of drug developments}

Drug development and manufacture are pillar industry for many developed countries, which is one of the highest competitive areas worldwide. Nevertheless, anticancer drug discovery, development and manufacture have been entering bottleneck stages [3-6]. Now increasing amount of money is paid for drug screening, mechanistic studies and developments, it therefore results in a great rise of research fee in a whole process of each anticancer licensing (1-2 billion US dollar) in US and other developed countries-highly adventurous if an agent fails to be licensed or face withdrawal [5-6].

\section{System evolution}

Despite slow improvements, the property of current drug development systems (complicated and high cost) offsets the outcomes of clinical practice, especially for cancer metastasis treatments [711]. Thus, it is a difficult situation for anticancer drug discoveries and developments. Serious impacts for unhealthy progression of drug development and industry loom over the globe [14-16]. However, as a good sign of medical and pharmaceutical circle, anticancer drug development systems and routines are constantly evolving. These kinds of biomedical/pharmacological efforts are the positive side of anticancer drug developments.

\section{Current systems in utility}

To better utilize new scientific discoveries and technical advancements, different patterns of anticancer drug characters must not be neglected. Present anticancer drugs are characterized as following limitations and drawbacks.

\section{Scenarios of current anticancer drug development}

1. Different therapeutic modality: The different therapeutic modalities of anticancer drugs (wide-spectra and narrow-spectra) and targets (apoptic, cancer suppressor genes and neoplasm metastasis) on different types of cancer genes, biological molecules and cellular mechanisms. Future experimental or preclinical tumor models should be categorized into different series and be studied by different types of potential anticancer agents and combinations. Specificity is the key.

2. Tumor model narrow-down or broad-up: Present in vitro or in vivo animal or human tumor models are enormously diversified [3-5]. Proper budget control mechanisms must be introduced and necessary. Yet most of these animal or human tumor models have lost their original genotypes or phenotypes by long passages in vitro

${ }^{\star}$ Correspondence to: Da-Yong Lu, School of Life Science, Shanghai University, Shanghai, PR China, E-mail: ludayong@shu.edu.cn

Key words: anticancer drug development, neoplasm metastasis, cost-effective, natural chemotherapeutic drugs, tumor modality, drug toxicology, systems biology, cancer stem cells, metastatic model

Received: September 03, 2018; Accepted: September 21, 2018; Published: September 26, 2018 
or in vivo [5]. Tumor modal either narrow-down or broad-up is indispensable route for future anticancer cancer drug developments and system updating [3-4].

3. Tumor origin and inoculation variations: Different tumor inoculation routes or animal models in experimental or preclinical studies vary for compound responses/efficacy to tumors and biomedical data statistical analysis. Tumor inoculation sites or locations (subcutaneous implantation of tumor tissues), intraperatoneal (ip), intravenous (iv), hollow-fiber (HF), othortopic, carcinogen-induced and so on for anticancer or antimetastatic activity testing may vary drug evaluation outcomes in initial stage of drug discovery. Moreover, tumor recipients (immune-deficient animals, normal animals or genetic engineering mice models (GEMM) and so on) may impact therapeutic outcomes of drug activity and mechanisms of drug developments. Similarity, tumor environments that tumor tissues originally survives and progresses in human bodies must be separately studies $[12,13]$.

4. Anti-metastatic drug developments: Antimetastatic agents or drugs developments need to be boosted because $90 \%$ cancer deaths are caused by neoplasm metastasis, especially for aged cancer patients. Despite increasingly understanding of aspects of many fundamental biology and pathology of neoplasm metastasis, their therapeutic mechanisms of action have been commonly neglected, especially concept of translation technology. Few antimetastatic agent or drug has shown high therapeutic benefits in patients with a long-term of neoplasm metastases [7-11]. Shortage of wider-spectra antimetastatic drugs is a serious drawback for clinical therapeutic utility.

With these anticancer drug characterizations, we need to find new solutions from every new scientific discovery and technical innovations (Figure 1).

\section{Evolving of anticancer drug screening models}

\section{From drug response to drug resistance to gene-knockout to tumor stroma}

Tumor models update with times from emerging pharmacological purposes (Figure 1). Though in vitro or in vivo tumor models have been constantly evolving like the situations of Figure 1, the overall outlook of anticancer drug development systems has been evolving silently. So far, we did not hit the bull's eye of anticancer drug developments while we are approaching our ultimate goals. We have to welcome all smart ideas (such as angiogenesis or cancer stem cell inhibitors) for pathological processes/pharmacologic evaluation (genomic or mathematical networks). Yet any small pieces of biological or pathologic information may finally help us to jigsaw a wholesome picture of cancer and buildup of effective drug intervention pathways. From the situations of tumor modality updating, the latest tumor models are costlier and eye on minute details. Thus, it is not the time to debate or nullify previously discovered processes. It is the time to integrate and jigsaw these pieces and puzzle altogether-keep the pace of anticancer drug development evolution.

\section{Facing with a great diversity of biomedical information}

The dynamic mechanisms of action study for oncogenic- and metastatic- genes are of great scientific and clinical values. Nonetheless, this stage of drug screening systems has a wide-spectra of tumor models for therapeutic verification and clinical utilities. The reason behind scene is attributable to the following;

\section{Normal tumor cells/models}

(From animal or human tumors)<smiles>C=[AlH2]</smiles>

\author{
Biological selections \\ (B16-F1-10 and so on)
}<smiles>[AlH]C=[V]</smiles>

Pharmacological selections

(Drug-resistant tumor cell lines and so on)

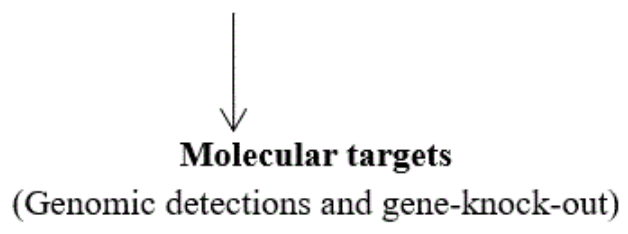

Figure 1. The outlook of tumor cell lines innovations

\section{Long passage of tumor models}

There are approximately 1,200 human cancer cell lines in conventional drug study labs. However, these tendency of growing types of human cell lines share many similarity properties after long passage of human tumor cells in in vitro or in vivo. If we keep on this route, a lot of money will be wasted away. Ingenious solution must follow up.

\section{Tumor stroma as a therapeutic target}

Tumors in cancer patients are more than tumor cells alone. Tumor stroma, though varying in contents and ratio, also play key roles in tumor growths and metastasis $[17,18]$. As one of the top controversies, tumor stroma as a therapeutic target is receiving growing attentions from medical circle. However, this tumor modality is unable to fit clinical requirements or benefits despite experimental successes. Further work and action are needed in the field of cancer therapeutic study. Due to more complicate situations under clinical environments than experimental conditions, further scientific exploration towards human vasculatures and stroma is indispensable. It includes new generation of metastatic modality in the future.

\section{Tumor metastatic models}

Antimetastatic drug developments need to be updated with times because $90 \%$ cancer mortality is caused by neoplasm metastasis, especially for aged cancer patients. Until now, few antimetastatic agent or drug exhibits any therapeutic survival benefits for patients with neoplasm metastases [3-6]. This is the most important failure of cancer drug treatments in the clinic. The unnoticed causality must be found out lately.

Currently, many compounds that can greatly inhibit tumor metastasis in animal models fail to show any therapeutic survival benefits in cancer patients clinically. It is probably caused by lack of good animal tumor models for antimetastatic drug developments [19]. Present available tumor metastatic models (Lewis lung carcinoma and B16) are observed for tumor colony in lung (pulmonary metastasis). However, there are a lot of human organs that can host metastatic 
cells and colony. Human brain, liver, bone and abdominal areas are all vulnerable to tumor invasion and metastasis [19]. As a result, a lot of other good metastatic models (seeking lodging on tissues of bone, brain, liver and others) must be utilized in antimetastatic drug evaluations. This process of drug evaluation might need larger sized animal tumor models (such as dogs, monkey and so on). More recently, it is believed that neoplasm metastasis is a changeable pathological process [20] that can either traverse from beginning to end or reverse back from end to beginning [11]. It is unsuitable for evaluating from a fixed tumor metastatic model.

\section{Avart-garde equipment and lab facilities}

Apart from animal or human tumor models, avant-garde experimental equipment and lab facilities impact on the quality of drug evaluations. Modern diagnostic equipment making drug identifications and verification more objectively and scientifically are our future targets. Here are the several examples that a modern lab may require and be equipped with;

\section{Cutting-edge lab devises for drug evaluations}

Electric tumor volume detectors

Magnetic resonance imaging (MRI)

Positron emission tomography (PET)

Bioluminescent imaging

Modern chromatography (HPLC-MS, GC-IR, GC-MS etc.)

Next generation sequencing machine

Tumor biomarker detection (Automatic Western blot devise etc.)

Different bioinformatics techniques and equipments and so on.

Besides animal or human tumor models, avant-garde equipment and facilities, the quality of anticancer drug discovery pipelines and therapeutic efficacy comparisons are improving in modern days (Figure 2). It may not only save time of researchers, but also know biomedical information previously neglected in labs and hospitals. Nonetheless, advancements of new anticancer drug discovery vary between labs and countries, which make a great difference in drug developments. Entering this Millennium, clinical verification often fails with the blind-spot of many pharmacological knowledge in clinical evaluation processes. Strangely enough, advancements of tumor models and automatic detection equipments help us to reclaim many withdrawal anticancer drugs or transformations of drugs licensed for other disease categories into part of the arsenal of cancer therapy [15,21]. Only times can solve these therapeutic enigma and lead to better clinical practice for wide-range of cancer patients.

\section{New frontiers}

\section{Good governance of drug development}

Good governmental policy and regulatory network for drug developments and internationally protections of intellectual property rights might build up healthy revolutionary mechanisms for scenario changes. After all, we can finally benefit the globes through stronger national tie and dialogues. But the regulatory network does not function well nowadays. Different barriers exist everywhere among different countries. The contradictory regulatory systems aiming at national protections are present across the world. Most of them are the causality of social variations and isolation. As a result, general assembly

\section{Tumor models}

(Cell numbers and volumes)

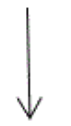

Biomarkers

(Biochemical \& omics)

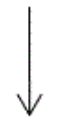

Cancer genes

(Microarray, SNP, genomic and so on)<smiles>C=[AlH2]</smiles>

\section{Non-invasive}

(Morphologic image_-PET \& bioluminescence)

Figure 2. Outlook of modern diagnostics evolutions in drug evaluations

and conference must be organized to discuss them worldwide. After these efforts and effective actions, more healthy regulatory systems will be stepped up.

\section{Different drug combinations}

Anticancer drug combinations of each possibility often show many unexpected therapeutic outcomes in the clinic $[22,23]$. From our own perspectives, these researches should be included in drug developments in the future.

Evaluating the different drug combinations is a new avenue for anticancer drug studies [24,25]. Only after these systematic efforts, anticancer drug combinations can be transformed from preliminary experimental data into clinical paradigms/achievements. Previously, large volume of drug combinatorial information is undertaken directly in the clinic. Many unlicensed compounds that have no anticancer efficacy cannot be studied in clinical circumstances, yet they can make chemistry with licensed anticancer drugs in many reality conditions. To conclude, we shall follow up these branches of drug developments in the future $[22,23]$.

\section{Therapeutic ideas against neoplasm metastasis}

Cancer is a malignant disease that is often difficultly inhibited or cured in the clinic. Despite great advances in recent decades, current cancer metastasis therapy has been little improved, especially shortages of effective antimetastatic drugs [7-11] etc. Smarter ideas to solve this issue must be found out. However, these kinds of pharmacological efforts must be based on updating pathological knowledge [26-34].

\section{Association between tumor model selection and drug develop quality}

After long observations, it is found that different tumor models will yield different types of anticancer drugs. In the initial anticancer drug screen stage (before mid-1970s), murine leukemia cell lines (P388 and L1210) was used for anticancer drug discovery. At that time, antiproliferative drugs (DNA chelating agents and so on) have commonly been found out. Lately, 6 murine tumors and two human colon tumor 
xenografts were widely used in drug screening. Among the utility of this tumor model system, growing numbers of anticancer drugs have been found (mainly cytotoxic anticancer drugs-targeting on DNA level).

More recently (after 1990), biological (antibody or bio-agents) or targeted chemical drugs (genetic or molecular-oriented) have been widely licensed from the systematic study of cancer biology \& pathology. A strong association between tumor models and drug develop quality is an obvious event globally (Figure 3).

Given from a great variety of tumor models $(>5,000$ different tumor cell lines and 1,000 number of tumor models in living bodies worldwide), new types of tumor models (both tumor cells and stroma) will still be useful for anticancer drug development.

\section{Pharmaceutical characters and evolution}

Pharmaceutical character of anticancer drugs is a useful avenue to improve cancer therapies. Different pharmaceutical forms of anticancer drugs may vary in therapeutic efficacy against tumor growth and remote dissemination. May the Nano anticancer drug, an emerging topic of cancer therapeutic approach make a difference in clinical trials? A lot of references support this scenario and want to promote Nano-technology into anticancer drug utilization [35-37]. Yet, certain numbers of these references exaggerate these therapeutic efficacy and clinical applications. At least, no market breakthrough in this respect has been achieved so far. Though different pattern of Nano-particles has been invested, central debate remains. Some early articles even stated that many normal chemical drugs have same penetrating capability and therapeutic benefits in many clinical circumstances [37]. If we pay no heed to these exaggerations, government funding or healthy financial investments will be damaged for good. Certainly, we must not lose our hope on Nano-drug developments. By wiser steps and persistent efforts, great breakthrough can be expected.

Apart from Nano-technology, drug administrating routes and doses are also very important to therapeutic responses and benefits in

Murine leukemia cells

(Anti-proliferative drugs)<smiles>C=C[AlH]</smiles>

Six murine and two human tumor models (Cytotoxic drugs)<smiles>C1CCCCC1</smiles>

Mechanisms of action

(Targeted drugs)

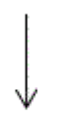

Comprehensive tumor models

(New anticancer drugs and antimetastatic drugs)

Clinical therapeutic options

(Modern diagnostics and workable drug combinations)

Figure 3. Association between tumor models and drug develop outcomes the clinic. In the past, it is widely believed that targeted anticancer drugs must be low toxicity to human beings. Yet, it is proved to be a wrong concept. Targeted anticancer drugs are also very toxic in high doses in the clinical settings [38]. These pharmaceutical and pharmacological studies should not be carried out in a single modality. Balancing the risks and efficacy of drugs is indispensable part of clinical cancer managements.

\section{Central medical/pharmacologic spotlights}

\section{Top deadliest causality for therapeutic failures}

Cancer chemotherapy faces two most difficult problems, neoplasm metastasis and multi-drug-resistances (MDR). Among these two thorny problems, treatment of neoplasm metastasis is especially difficult, which should be placed on the highest agenda at the stage of drug screening and developments. Also, metastasized tumors often concomitantly manifest the characters of MDR. Since more than $90 \%$ cancer deaths are caused by these two causalities. Possible associations between two pathogenesis and cancer stem cells (they can regenerate themselves in solid tumor tissue) might be a hot future topic. It is logical to believe that growing attentions should be paid on them [39-41]. Yet, no breakthrough has been found from therapeutic points of view [39]. It is due to only small proportion of cancer stem cells at present in tumor tissue (10\%). This small proportion of cancer stem cells cannot be easily noticed in most tumor tissues. Further work is needed. In future, new tumor models will be established for evaluating overall drug activity to cancer stem cells, drug resistance, drug combination and neoplasm metastasis.

\section{Chemical and biological property for anticancer drug study}

Optimal compound combinations, dose ranges, administered schedules and therapeutic duration in animal models and in humans are theoretically difficult to obtain completely. But they can be improved by modern chromatography (high performance liquid chromatography and gas chromatography-HPLC and GC) and positive/negative sample control. Novel approaches are given as followings. However, active drugs can be metabolized into several different forms. Each form of drug degrades shows different scale of biological activity. Currently, many anticancer drug treatments of PG are utilized for these types of therapeutic studies [42-48]. Yet, they are commonly occurred in the clinic. In the future, simulating systems in vitro or computational simulation might be utilized in drug absorption, distribution, metabolism and excretion (ADME) evaluations in experimental stages.

The discovery chemical states of active compound can deepen our understanding to relationship between cancer diagnosis and therapeutic outcomes (patho-therapeutic relations). This is a golden rule for improving cancer therapy and drug developments. However, cancer is greatly diversity with tissue origin/type and etiology causality of cancer genetics. Oncogenes can be in variety states; pan (universal present) and specified (present in a small sub-type of tumor cell lines) [49-53]. Correspondingly, pinpointing tumor categories and genetic abnormality are not far away. By these avenues, anticancer drug developments can be transformed from random drug screening into pharmacologic/medicinal designing. This exponential growth of cancer genomic study will soon make a difference in cancer therapeutics.

\section{Major obstacles to overcome}

Several steps to improve drug screening protocols and systems are proposed. Some important obstacles must be overcome via updating a series of pharmaco-therapeutic efforts, including; 
1. As usual, pay more attentions to discover specific drug targets (cellular, molecular or genetic-related), signaling-pathways/ axial/loop. Systemic analysis of drug response differences among experimental animal or human tumor growths and metastases must be formally established. Utility of those animal or human tumor models into mechanisms of action or/and clinical studies must transit from random to scientific-guided approaches. Keeping pace with those efforts not only accumulate medical knowledge, but also save money of both pharmaceutical companies and cancer patients.

2. To reduce development cost, especially BRICS countries or even poorer countries, ask their own-rights (the great amounts of cancer patient resources) will benefit both developing and developed countries [3]. To these countries like BRICS community, if they shoulder more pharmaceutical responsibility other than just publishing some medical/pharmaceutical articles in international journals. Given these new efforts, wider ranges of cancer patients will benefit.

3. Boost fundamental and scientific study the relationship between cancer biology, pathology and therapeutics. Global dissemination of latest pharmaceutical knowledge and advancements increase the quality of anticancer drug developments.

4. Implement high quality drug tolerance and PD/PK study in animals or humans, which are important building-blocks of anticancer drug development. Nevertheless, this is an endless enterprise and varied among different individuals. Balanced toxicological evaluating systems under pre-clinical and/or clinical circumstances must be promoted.

5. Find out active inhibitor and combination against neoplasm metastasis and cancer stem cells is one of the top priorities [3-6].

6. Modifying tumor models tailored for different patterns of therapeutic drugs and options, such as biotherapy, natural chemotherapeutic agents [54-56] or immunotherapy [57] is a future trend. Biotherapy or immunotherapy are emerging powers to combat cancer growth and metastases in clinical trials including neoplasm metastasis and drug-resistance [57]. Nonetheless, they are inappropriate to be evaluated by conventional drug screening or verification systems. Effective tumor modality for drug screening and marketing is indispensable. Creative actions for biotherapy as well as natural chemotherapeutic agent discoveries should be well carried out.

7. Genetic modifying animal or tumor models can receive useful acceptance for high-throughput diagnostics and therapeutics in the clinic before formal phase II \& phase III clinical evaluations [58-62].

\section{Reorganization of participant entities}

Drug development costs vary between drug types and manufacture countries [3-6,63]. A lot of money has been used for evaluation of drug responses to tumors and drug mechanisms of action expenditure including international article publications. Moreover, toxicological evaluations are limitless. The different categories of drug development costs are highlighted in the Figure 4. Balancing the expenditures of all branches of drug development is an ingenious enterprise. Yet, high quality study on specific original mechanisms of action for widely-used drugs is invaluable.

From Figure 4, not let each category of anticancer drug development branches go too far away from the rest of disciplines, especially article publication fee is the key. By these balanced types of drug development efforts, especially under-developed countries, drug development can be gradually fruitful and relatively profitable in a long-run.

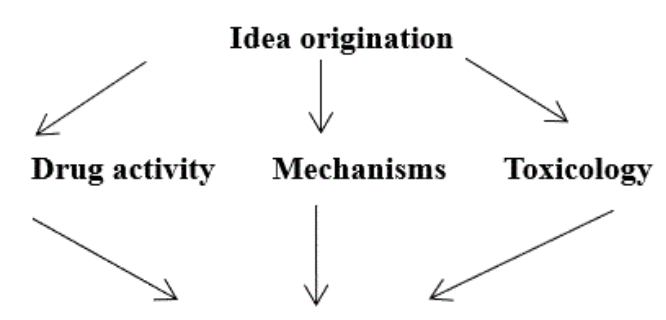

Intensive study

(Preclinical or clinical evaluation)

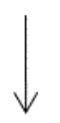

Article publication \& licensing<smiles>[AlH2]=[V]</smiles>

\section{Drug markets/withdrawal}

Figure 4. Economic conditions for drug discovery and developments

\section{Personalized medicine in drug developments}

Apart from finding enough active anticancer or antimetastatic drugs, good predictive models of drug utility in the clinic are also helpful to promote cancer treatments [64-66]. These efforts are called personalized cancer therapy or individualized cancer therapy (PCT/ICT) with disciplines of pharmacogenetics (PG) [42-48], drug sensitivity testing (DST) [67-70], cancer biomarker/bioinformatics [5963], anti-metastatic therapy [71], drug combinations $[23,24,72,73]$ and so on. Rapid progresses of PCT/ICT will be sooner or later transformed from bench to the bedside. In the future, increasing PG, DST or cancer biomarkers might be mandatory routines in clinical cancer practices in developed countries, even usual therapeutic options worldwide. As these medical disciplines are useful in the clinic, may hope them in the utility of drug development stages? Soon, we may receive positive feedback from our persistent efforts.

In future, both oncologic and pharmacological information should be considered simultaneously [74,75]. From this avenue, pharmacological study of anticancer agents will be wider accepted in $\mathrm{PCT} / \mathrm{ICT}$ in future.

\section{Global participation}

Since the high cost of anticancer drug development and licensing is required worldwide, joint-ventures between advanced pharmaceutical companies in industry countries, emerging economic entity or majorpart of developing countries might be a future solution for promotions of high quality of anticancer drug development and manufactures. Governmental or drug regulatory authorities may provide new stipulations for smoothly developments of drug licensing and clinical drug utilities. This might receive useful compromise or feedback through revising drug approval or licensing policy for more categories of anticancer drugs or medical systems, such as traditional Chinese medicine and so on [23].

\section{Outlook of future study}

Facing a lot of therapeutic dilemma at this stage of anticancer drug developments, some personal perspectives are included as: 
1. What is the key relationship between diversity of cancer subtypes (>200 subtypes) and therapeutic individualization [19]. The rigid drug evaluation and regulatory network forbid a healthy progress of anticancer drug developments due to this pathological diversity.

2. Many biological or pathological properties of cancers, such as neoplasm metastasis, drug resistance, cancer stem cells, cancer heterogeneity and plasticity are unclear to us. As a result, new anticancer drugs must be based on random experimental screening and clinical validations. This low-efficiency process increases the unpredictable and high-expenditure of drug development.

3. Since neoplasm metastasis is responsible for $90 \%$ cancer deaths worldwide, is there any difference between anticancer drugs and anti-metastatic drugs? [3-10]

4. Is current clinical therapeutics against neoplasm metastasis is on the right track? If it is not so, how can we adjust our future antimetastatic therapeutics in the clinic? $[19,20]$

5. Why the natural chemotherapeutic drugs commonly have a higher therapeutic index? [54-56]

6. The unbalanced revenues between drug developers (highly developed countries) and drug markets (developing countries) produce significant fracture worldwide.

7. How cancer genomic difference (somatic mutation, DNA methylation, sequence copy number changes and gene expression) changes with drug activity? [49-53]

8. Can we utilize more mathematical or computational network to reduce money investments? [76-85]

\section{Conclusion}

The anticancer drug development is constantly evolving and advancements. Mastering the essence of these drug development system evolution will facilitate our efficiency of drug discovery and marketing (cost reduction). Two future avenues might be gone through; (i) promote the efficacy of drug screening processes; (ii) optimally control drug development expenses. These are important topics and subjects for drug developments and manufactures internationally. In the future, more creative tumor growth or metastasis models as well as regulatory measures must be implemented from modernizing lab facilities and their association between tumor proliferation and metastasis control. We look forward to a new era of anticancer drug discovery and developments lately [86].

\section{Final remark}

More recently, we always reflect with a problem of anticancer drug development - a matter of money or a matter of idea? [87] Certainly this intertwine question will accompany us very long. Let's time tell us more. In that time, anticancer drug developments may be perfect.

\section{Acknowledgements}

This work was funded by Shanghai Science and Technology Foundation of High Educations 97A49.

\section{Competing interesting}

Authors have declared that no competing interests exist.

\section{References}

1. Siegel RL, Miller KD, Jemal A (2017) Cancer Statistics, 2017. CA Cancer J Clin 67: 7-30. [Crossref]
2. Ali I, Rahis-ud-din, Saleem K, Aboul-Enein HY, Rather A (2011) Social aspects of cancer genesis. Cancer Therapy 8: 6-14

3. Lu DY, Lu TR, Chen EH, Xu B, Yarla NS, et al. (2-17) Anticancer drug development, system updating and global participations. Current Drug Therapy 12: 37-45

4. Lu DY, Lu TR, Zhu H, Ding J, Xu B, et al. (2017) Anticancer drug development, getting out from bottleneck. Med Chem (LA US) 7: 739-744.

5. Suggitt M, Bibby MC (2005) 50 years of preclinical anticancer drug screening empirical to target-driven approaches. Clin Cancer Res 11: 971-981. [Crossref]

6. Talmadge JE, Singh RK, Fidler IJ, Raz A (2007) Murine models to evaluate novel and conventional therapeutic strategies for cancer. Am J Pathol 170: 793-804.

7. Mina LA, Sledge GW Jr (2011) Rethinking the metastatic cascade as a therapeutic target. Nat Rev Clin Oncol 8: 325-332. [Crossref]

8. Lu DY, Lu TR (2010) Antimetastatic activities and mechanisms of bisdioxopiperazine compounds. Anticancer Agents Med Chem 10: 564-570.

9. Lu DY, Lu TR, Cao S (2012) Cancer metastases and clinical therapies. Cell Dev Biol 1: e110.

10. Lu DY, Lu TR, Wu HY, Cao S (2013) Cancer Metastasis treatments. Current Drug Therapy 8: 24-29.

11. Lu DY, Lu TR, Xu B, Qi RX, Sastry NY, et al. (2016) Cancer metastasis, a clinical dilemma for therapeutics. Current Drug Therapy 11: 163-169.

12. Lu DY, Lu TR, Wu HY (2014) Personalized cancer therapy, a perspective. Clinical Experimental Pharmacology 4: 153

13. Lu DY (2014) Personalized cancer chemotherapy, an effective way for enhancing outcomes in clinics. Woodhead Publishing, Elsevier, UK.

14. Lu DY, Lu TR, Wu HY (2009) An overview of enhancing the international competitiveness for drug researches, development and manufactures in China. Chin Med Biotechnol 4: 465-467.

15. Gupta SC, Sung B, Prasad S, Webb LJ, Aggarwal BB (2013) Cancer drug discovery by repurposing: teaching new tricks to old dogs. Trends Pharmacol Sci 34: 508-517. [Crossref]

16. Ruggeri BA, Camp F, Miknyoczki S (2014) Animal models of disease: Preclinica animal models of cancer and their applications and utility in drug discovery. Biochemical Pharmacology 87: 150-161.

17. Dvorak HF (2015) Tumor Stroma, Tumor Blood Vessels, and Antiangiogenesis Therapy. Cancer J 21: 237-243. [Crossref]

18. Dvorak HF, Weaver VM, Tlsty TD, Bergers G (2011) Tumor microenvironment and progression. J Surg Oncol 103: 468-474. [Crossref]

19. Lambert AW, Pattabiraman DR, Weinberg RA (2017) Emerging Biological Principles of Metastasis. Cell 168: 670-691. [Crossref]

20. Nieto MA, Huang RY, Jackson RA, Thiery JP (2016) EMT: 2016. Cell 166: 21-45. [Crossref]

21. Ali I, Wani WA, Saleem K, Haque A (2012) Thalidomide: a banned drug resurged into future anticancer drug. Current Drug Ther 7: 13-23.

22. Lu DY, Chen EH, Wu HY, Lu TR, Xu B, et al. (2017) Anticancer Drug Combinations, How Far We can Go Through? Anticancer Agents Med Chem 17: 21-28. [Crossref]

23. Lu DY, Lu TR, Yarla NS, Wu HY, Xu B, et al. (2017) Drug Combination in Clinical Cancer Treatments. Rev Recent Clin Trials 12: 202-211. [Crossref]

24. Lu DY, Chen EH, Lu TR, Ding J (2014) Anticancer drug combinations, studies from different pathways. Cell Dev Biol 4: 166.

25. Lu DY, Chen EH, Lu TR, Ding J (2016) Anticancer drug combinations, studies for all possibilities. Adv Pharmacoepidemiol Drug Saf 5: e138.

26. Fidler IJ (2003) The pathogenesis of cancer metastasis: the 'seed and soil' hypothesis revisited. Nat Rev Cancer 3: 453-458. [Crossref]

27. Gupta GP, Massagué J (2006) Cancer metastasis: building a framework. Cell 127: 679695. [Crossref]

28. Talmadge JE, Fidler IJ (2010) The biology of cancer metastasis: historical perspective. Cancer 70: 5649-5669.

29. Valastyan S, Weinberg RA (2011) Tumor metastasis: molecular insights and evolving paradigms. Cell 147: 275-292. [Crossref] 
30. Sava G, Bergamo A (1999) Drug control of solid tumour metastases: a critical view. Anticancer Res 19: 1117-1124. [Crossref]

31. Kessenbrock K, Plaks V, Werb Z (2010) Matrix metalloproteinases: regulators of the tumor microenvironment. Cell 141: 52-67. [Crossref]

32. Taraboletti G, Margosio B (2001) Antiangiogenic and antivascular therapy for cancer. Curr Opin Pharmacol 1: 378-384. [Crossref]

33. Wang L, McLeod HL, Weinshilboum RM (2011) Genomics and drug response. $N$ Engl J Med 364: 1144-1153. [Crossref]

34. Herter-Sprie GS, Kung AL, Wong KK (2013) New cast for a new era: preclinical cancer drug development revisited. J Clin Invest 123: 3639-3645. [Crossref]

35. Ali I (2011) Nano anti-cancer drugs: pros and cons and future perspectives. Curr Cancer Drug Targets 11: 131-134. [Crossref]

36. Ali I, Rahis-Uddin, Salim K, Rather MA, Wani WA, et al. (2011) Advances in nano drugs for cancer chemotherapy. Curr Cancer Drug Targets 11: 135-146. [Crossref]

37. Wilhelm S, Tavares AJ, Dai Q, Ohta S, Audet J, et al. (2016) Analysis of nano-particle delivery to tumors. Nat Rev Materials 1: 14.

38. Prasad V, Massey PR, Fojo T (2014) Oral anticancer drugs: how limited dosing options and dose reductions may affect outcomes in comparative trials and efficacy in patients. J Clinical Oncol 32: 1620-1630. [Crossref]

39. Yakisich JS (2012) Challenges and limitations of targeting cancer stem cells and/or the tumour microenvironment. Drug and Therapy Study 2: e10.

40. Park TS, Donnenberg VS, Donnenberg AD, Zambidis ET, Zimmerlin L (2014) Dynamic interactions between cancer stem cells and their stromal partners. Curr Pathobiol Rep 2: 41-52. [Crossref]

41. Magee JA, Piskounova E, Morrison SJ (2012) Cancer stem cells: impact, heterogeneity, and uncertainty. Cancer Cell 21: 283-296. [Crossref]

42. Watters JW, Mcleod HL (2003) Cancer pharmacogenomics: current and future applications. Biochim Biophys Acta 1603: 99-111. [Crossref]

43. Efferth T, Volm M (2005) Pharmacogenetics for individualized cancer chemotherapy. Pharmacol Ther 107: 155-176. [Crossref]

44. Huang RS, Ratain MJ (2009) Pharmacogenetics and pharmacogenomics of anticancer agents. CA Cancer J Clin 59: 42-55. [Crossref]

45. Patel JN, Fuchs CS, Owzar K, Chen ZH, McLeod HL (2013) Gastric cancer pharmacogenetics: progress or old tripe? Pharmacogenomics 14: 1053-1064.

46. André F, Ciccolini J, Spano JP, Penault-Llorca F, Mounier N, et al. (2013) Personalized medicine in oncology: where have we come from and where are we going? Pharmacogenomics 14: 931-939. [Crossref]

47. Meyer UA (2004) Pharmacogenetics - five decades of therapeutic lessons from genetic diversity. Nat Rev Genet 5: 669-676. [Crossref]

48. Lu DY, Lu TR, Xu B, Ding J (2015) Pharmacogenetics of cancer therapy: breakthroughs from beyond? Future Sci OA 1: FSO80. [Crossref]

49. Lander ES (2011) Initial impact of the sequencing of the human genome. Nature 470: 187-197. [Crossref]

50. Braggio E, Egan JB, Fonseca R, Stewart AK (2013) Lessons from next-generation sequencing analysis in hematological malignancies. Blood Cancer J 3: e127.

51. Garraway LA, Lander ES (2013) Lessons from the cancer genome. Cell 153: 17-37. [Crossref]

52. Huang YH, Vakoc CR (2016) A Biomarker Harvest from One Thousand Cancer Cell Lines. Cell 166: 536-537. [Crossref]

53. Iorio F, Knijnenburg TA, Vis DJ, Bignell GR, Menden MP, et al. (2016) A Landscape of Pharmacogenomic Interactions in Cancer. Cell 166: 740-754. [Crossref]

54. Ali I, Saleem K, Uddin R, Haque A, El-Azzouny A (2010) Natural products: human friendly anti-cancer medications. Egypt Pharm J (NRC) 9: 133-179.

55. Rumschlag-Booms E, Zhang HJ, Soejarto DD, Fong HHS, Rong LJ (2011) Development of an antiviral screening protocol: one-stone-two-birds. J Antivir Antiretrovir 7: 8-10.

56. Lu DY, Lu TR, Lu Y, Sastry N, Wu HY (2016) Discover natural chemical drugs in modern medicines. Metabolomics 6: 181.

57. Couzin-Frankel J (2013) Breakthrough of the year 2013. Cancer immunotherapy. Science 342: 1432-1433. [Crossref]
58. Lu DY, Lu TR, Chen XL, Chen EH, Ding J, et al. (2015) Cancer bioinformatics, its impacts on cancer therapy. Metabolomics 5: e133.

59. Ocaña A, Pandiella A (2010) Personalized therapies in the cancer "omics" era. Mol Cancer 9: 202. [Crossref]

60. Stransky B, Galante P (2010) Application of bioinformatics in cancer research. An IMICS Perspective on Cancer Research 2010: 211-233.

61. Lu DY (2014) Individualized cancer chemotherapy via cancer biomarkers or bioinformatics detecting. Personalized Cancer Chemotherapy, An Effective Way for Enhancing Outcomes in Clinics. Ed, Lu DY, Chapter 3, Woodhead Publishing, Elsevier, UK, pp: 13-20.

62. Lu DY, Qi RX, Lu TR, Wu HY (2017) Cancer bioinformatics for update anticancer drug developments and personalized therapeutics. Rev Recent Clin Trials 12: 101-110. [Crossref]

63. Lu DY, Lu TR, Wu HY (2013) Cost-effectiveness considerations of individualized cancer chemotherapy. Adv Pharmacoepidemiol Drug Saf 2: e121.

64. Lu DY, Chen XL, Ding J (2006) Individualized cancer chemotherapy integrating drug sensitivity tests, pathological profile analysis and computational coordination-an effective strategy to improve clinical treatment. Med Hypotheses 66: 45-51. [Crossref]

65. Lu DY, Lu TR, Chen XL, Ding J (2012) Individualized cancer chemotherapy. Hypotheses in Clinical Medicine. Ed, Shoja MM, Agutter PS, Tubbs RS, Ghanei M, Ghabili K, Harris A, Loukas M. chapter 13, Nova Science Publisher. US, pp: 199-216.

66. Lu DY, Lu TR, Che JY, Wu HY (2014) Individualized cancer therapy. Innov Pharm Pharmacother 2: 414-425.

67. Lu DY, Lu TR, Ding J, Xu B, Che JY, et al. (2015) Anticancer drug sensitivity testing, a historical review and future perspectives. Current Drug Therapy 10: 44-55.

68. Lu DY (2014) Drug sensitivity testing. Personalized Cancer Chemotherapy, An Effective Way for Enhancing Outcomes in Clinics. Ed, Lu DY, Chapter 2, Woodhead Publishing, Elsevier, UK, pp: 5-12.

69. Volm M, Efferth T (2015) Prediction of Cancer Drug Resistance and Implications for Personalized Medicine. Front Oncol 5: 282. [Crossref]

70. Ugurel S, Schadendorf D, Pfohler C, Neuber K, Thoelke A, et al. (2006) In vitro drug sensitivity predicts response and survival after individualized sensitivity directed chemotherapy in metastatic melanoma: a multicenter phase II trial of the dermatologic cooperative oncology group. Clin Cancer Res 12: 5454-5463.

71. Lu DY, Xi YC (2012) Antimetastatic therapy according to metastatic cascade. $A d v$ Pharmacoepidemiol Drug Saf 1: e107.

72. Lu DY (2014) Drug combinations. Personalized Cancer Chemotherapy, An Effective Way for Enhancing Outcomes in Clinics. Ed, Lu DY, Chapter 6, Woodhead Publishing, Elsevier, UK, pp: 37-42.

73. Lu DY, Chen EH, Lu TR, Ding J, Xu B (2015) Anticancer drug combinations: the next medical challenge. Innov Pharm Pharmacother 3: 637-649.

74. Lu DY, Lu TR, Xu B, Ding J, Yarla NS (2017) General topics in the field of personalized cancer therapy. Metabolomics 7: e001.

75. Lu DY, Lu TR, Xu B, Ding J, Yarla NS (2017) Clinical cancer therapy, personalized chemotherapies. J Cell Dev Biol 1: 5 .

76. Lu DY, Lu TR, Ding J (2007) Employing new mathematical models and equations to evaluate risk-benefit criteria of clinical therapeutics. Online J Biological Science 7: 1-2

77. Waterman MS (2000) Introduction to computational biology; maps, sequence and genomes. CRC Press, Taylor Francis Group LLC, US.

78. Komarova NL (2006) Mathematical modeling of tumorigenesis, mission possible. Curr Opin Oncol 17: 39-43. [Crossref]

79. Khalil C (2006) System biology for cancer. Curr Opin Oncol 17: 44-48.

80. Lu DY, Lu TR (2015) Mathematics or physics-majored students on the biomedical fields, insiders or outsiders? Metabolomics 5: e142.

81. Lu DY, Wu HY, Lu TR, Che JY, Lu Y (2016) Updating biomedical studies by recruiting more mathematics or physics-majored talents. Metabolomics 6: e148.

82. Loewe L (2009) A framework for evolutionary systems biology. BMC Syst Biol 3: 27. [Crossref]

83. Werner HM, Mills GB, Ram PT (2014) Cancer Systems Biology: a peek into the future of patient care? Nat Rev Clin Oncol 11: 167-176. [Crossref] 
84. Kherlopian AR, Song T, Duan Q, Neimark MA, Po MJ, et al. (2008) A review of imaging techniques for systems biology. BMC Syst Biol 2: 74. [Crossref]

85. Lu DY, Lu TR, Lu Y, Wu HY, Yarla NS (2017) The acquisition of mathematical language in biomedical articles. J Cell Developmental Biol 1: 8 .
86. Lu DY, Lu TR, Yarla NS, Xu B, Chen EH, et al. (2017) Anticancer drug development, breakthroughs are waiting. Adv Pharmacol Clin Trials 2: 119.

87. Lu DY, Chen EH, Lu TR (2015) Anticancer drug development, a matter of money or a matter of idea? Metabolomics 5: e134.

Copyright: C2018 Lu D. This is an open-access article distributed under the terms of the Creative Commons Attribution License, which permits unrestricted use, distribution, and reproduction in any medium, provided the original author and source are credited. 